and Environment there. Mearns says social scientists within the institute will continue to work with physical scientists at NCAR on integrated research projects. "And that's the proper role for an institute in social science at NCAR."

On the other side, some scientists are questioning whether the institution has done enough to maintain, let alone build, its expertise in the physical sciences, particularly in climate modelling. These questions have been driven home by the departure of key scientists, including William Collins, who helped oversee NCAR's climate modelling programme. "I can tell you in the science divisions here, it's the worst mood people have seen in a long time, and one reflection is people walking away," says Caspar Ammann, a palaeoclimatologist at the institution.

NCAR's new director, Eric Barron, who took over in July, says the institution is in an "interesting position", caught between a dismal budgetary

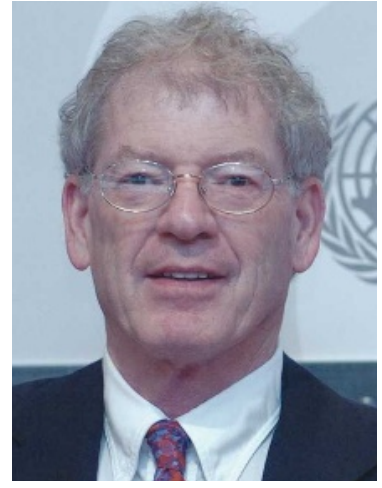

Mickey Glantz's social science department has been axed. positions throughout the institution "that are of critical importance" by eliminating a single programme that he says cost upwards of $\$ 730,000$ annually.

NCAR's base budget - almost $\$ 88.5$ million in the fiscal year 2008 - comes from the US National Science Foundation, although the institution receives significant funding from other federal agencies as well. In the fiscal year 2007 , its overall budget came to $\$ 149.3$ million. Although current appropriations bills in Congress would increase NCAR's budget, few expect this legislation to pass in an election year. Congress is likely to wind up passing a "continuing resolution" later this autumn that would effectively freeze current spending levels until at least early next year.

Roger Pielke Jr, a climate policy expert at the Center for Science and Technology Policy Research at the University of Colorado at Boulder, says it's not clear why Glantz outlook and ongoing concerns about where NCAR should direct its limited resources. "A number of people are saying that our climate modelling programme has taken too big of a hit. People are saying very loudly that NCAR is not setting its priorities the way it should," he says. "The simple fact of the matter is that years of tight budgets are coming home to roost."

Barron says he supports the social science mission but was able to preserve several was singled out or, more broadly, how NCAR is addressing its fiscal situation. "There's really no transparency in how these decisions are made," he says.

Glantz, who has been guaranteed one year's salary, says he plans to stay on for a while, although such courtesies will not be extended to his staff, including an administrative position and two researchers.

Jeff Tollefson particles. The lightest supersymmetrical particles are expected to be both massive and stable - making them prime candidates for dark matter. Occasionally, theorists believe, two of these particles will smash together and annihilate each other in a burst of energy. The annihilation will create a stream of more conventional particles that will eventually decay, leaving energetic electrons and positrons. In other words, the positrons detected by PAMELA could be the direct result of dark-matter annihilations.

The detection is the second dark-matter claim by Italians in recent months. In April, scientists at the DAMA/LIBRA (Dark Matter/ Large Sodium Iodide Bulk for Rare Processes) experiment, located beneath Italy's Gran Sasso mountain, claimed to have seen dark-matter particles (see Nature 452, 918; 2008). The PAMELA results are unconnected, and their suggested mass range for dark matter seems to contradict the DAMA claim.

PAMELA's findings are far from certain.
Identifying fast-moving positrons is extremely difficult, says Stefan Schael, a physicist at RWTH Aachen University in Germany. Their positive charge and high energies can make them look like ordinary protons, he says. Ideally, experiments would have two detectors capable of telling the difference, but PAMELA only has one. "They have only one chance for this identification," Schael says. "This is the main challenge for the group."

Even if the surplus exists, it could be from nearby astronomical sources. Objects such as neutron stars, pulsars and $\mathrm{X}$-ray binary stars are capable of making energetic positrons that would fool PAMELA. "When the data are released there will certainly be a large number of people looking at the question," says Hooper.

For now, however, the community is waiting with bated breath. As McElrath says: "We all wonder what's going on up there."

Geoff Brumfiel
ENVIRONMENT POLICY

Shake-up for Endangered Species Act.

www.nature.com/news

\section{Biodiversity body 'lacks science'}

Swedish researchers have launched a scathing attack on the scientific credentials of an international advisory body on biodiversity, warning that its effectiveness is being undermined by the increasing dominance of politicians and professional negotiators.

Their concerns about the work of the scientific body that advises the Convention on Biological Diversity (CBD) are widely shared, the convention's own executive secretary, Ahmed Djoghlaf, has told Nature. The convention has been signed by 168 countries who pledge to significantly reduce the current rate of biodiversity loss by 2010. Article 25 of the convention states that government representatives shall be "competent in the relevant field of expertise", but according to the Swedes, this is often not the case.

In a letter published in Conservation Biology, the ten scientists in the Swedish delegation to the $\mathrm{CBD}$ say that some parties to the convention are clearly trying to move away from science so that the convention does not interfere with trade and economic growth (L. Laikre et al. Conserv. Biol. 22, 814-815; 2008).

Per Wramner of Södertörn University College in Flemingsberg, who is one of the letter's authors, says that the February CBD meeting in Rome pushed them to act after it became bogged down in political wrangling and semantics. "This last meeting was a disaster from the scientific perspective," says Wramner, who chairs the Swedish government's CBD advisory group.

"Mexico and the European Union also expressed concern that there are too many new issues of procedure and of a policy nature," says Djoghlaf.

Conservation scientist Michael Stocking of the University of East Anglia, Norwich, UK, says that the nomination system is "the core of the problem, in that these tend to be government nominees ... not scientists who are up to date with the literature". Countries that fund the CBD will have to insist on change for it to actually happen, says Stocking, who is vice-chair of the Scientific and Technical Advisory Panel for the Global Environment Facility, which administers the funding for the CBD.

The concerns come amid attempts led by France to create a new international science policy group on biodiversity. Modelled on the same independent framework as the Intergovernmental Panel on Climate Change, this new body could mitigate some of the recently raised concerns. A 'concept note' for the new group was circulated last month by France. Daniel Cressey 